Original Research Paper

\title{
Penyuluhan Pembuatan Awetan Tumbuhan dan Hewan Sebagai Media Pembelajaran IPA
}

\author{
I Putu Artayasa ${ }^{1}$, Muhlis ${ }^{2}$, Agus Ramdani ${ }^{3}$ \\ ${ }^{1,2,3}$ Pendidikan Biologi Fakultas Keguruan dan Ilmu Pendidikan, Universitas Mataram, Indonesia
}

DOI: https://doi.org/10.29303/jpmpi.v4i2.832

Sitasi: Artayasa. I. P., Muhlis., \& Ramdani, A. (2021). Penyuluhan Pembuatan Awetan Tumbuhan dan Hewan Sebagai Media Pembelajaran IPA. Jurnal Pengabdian Magister Pendidikan IPA, 4(2)

\author{
Article history \\ Received: 30 April 2021 \\ Revised: 23 Mei 2021 \\ Accepted: 06 Juli 2021 \\ *Corresponding Author: I Putu \\ Artayasa, Pendidikan Biologi \\ Fakultas Keguruan dan Ilmu \\ Pendidikan, Universitas \\ Mataram, Indonesia \\ Email: \\ artayasa75@unram.ac.id
}

\begin{abstract}
Abstrak: Spesimen awetan tumbuhan dan hewan merupakan media pembelajaran yang sangat dibutuhkan untuk mengkonkritkan materi pembelajaran IPA khususnya pada materi biologi. Tujuan pengabdian adalah memberikan penyuluhan kepada guru SMPN 20 Mataram tentang teknik pembuatan awetan tumbuhan dan hewan. Penyuluhan dilakukan melalui metode diskusi, demonstrasi dan praktek pembuatan spesimen awetan tumbuhan dan hewan. Tumbuhan dan hewan yang diawetkan adalah makhluk hidup yang seringkali dijumpai siswa dalam kehidupan sehariharinya, seperti kupu-kupu, belalang, lebah, capung, kumbang, moluska, dan berbagai jenis tumbuhan berukuran kecil seperti tumbuhan paku rumputan. Spesimen awetan yang dibuat berupa awetan kering dan basah. Penyuluhan dilakukan oleh tim pengabdian yang terdiri dosen, laboran, dan mahasiswa FKIP Universitas Mataram, sementara peserta pengabdian terdiri 20 orang guru. Evaluasi terhadap efektivitas kegiatan pengabdian kepada masyarakat dilakukan melalui pengamatan keterlaksanaan pengabdian dan penyebaran angket kepada peserta untuk mendapatkan data dampak yang mereka peroleh setelah pengabdian dilakukan. Hasil pengabdian menunjukkan bahwa guru antusias membuat spesimen awetan kering berupa insektarium, herbarium, dan awetan cangkang moluska, serta awetan basah cacing dan ikan. Peserta pengabdian mendapatkan peningkatan wawasan dan keterampilan dalam membuat spesimen tumbuhan dan hewan. Kesimpulan dari pengabdian adalah penyuluhan yang dilakukan melalui diskusi, demonstrasi, dan pendampingan pembuatan spesimen awetan tumbuhan dan hewan berdampak meningkatkan pemahaman dan keterampilan peserta membuat awetan tumbuhan dan hewan tersebut.
\end{abstract}

Kata kunci: awetan kering tumbuhan dan hewan; awetan basah makhluk hidup; herbarium; insektarium; spesimen cangkang moluska; media praktikum biologi

dianggap sebagai media yang paling tepat untuk membelajarkan siswa tentang keanekaragaman makhluk hidup (Agustina, 2017). Pengamatan media riil tersebut dapat dilakukan secara langsung di habitatnya atau pengamatan awetannya. Pengamatan tumbuhan dan hewan tersebut biasanya dilaksanakan pada kegiatan praktikum di sekolah. 
Kegiatan praktikum selain memperkaya proses pembelajaran, juga merupakan pendukung utama kegiatan ekstrakurikuler di bidang IPA seperti penyusunan karya ilmiah remaja dan pembinaan olimpiade sains, serta menunjang prestasi siswa (Artayasa, 2017; Feyzioglu, 2009; Rati et al., 2017).

Ketersediaan spesimen awetan tumbuhan dan hewan sangat dibutuhkan dalam membantu pelaksanaan pembelajaran IPA karena disamping membantu meningkatkan pemahaman siswa, media awetan tersebut dapat disimpan relatif lama sehingga memudahkan guru memanfaatkannya setiap saat ketika dibutuhkan (Syamsiah, et al., 2020). Menurut Itiqomah (2014), penggunaan spesimen awetan tumbuhan dan hewan dalam pembelajaran biologi membantu meningkatkan kekaguman siswa tentang keberadaan makhluk hidup, dan meningkatkan kerja sama diantara siswa saat pembelajaran, serta meningkatkan ketuntasan belajar mereka. Spesimen awetan tumbuhan dan hewan dapat dibuat guru di laboratorium sekolah disamping dengan cara membelinya di toko alat dan bahan praktikum IPA Usaha guru IPA untuk menyediakan spesimen awetan tumbuhan dan hewan seringkali terkendala minimnya pengalaman guru membuat spesimen awetan tersebut terutama terjadi pada guru IPA yang berasal dari luar program studi Biologi atau Pendidikan Biologi seperti yang terjadi di SMPN 20 Mataram. Dengan demikian dibutuhkan upaya untuk meningkatkan pengetahuan dan keterampilan guru membuat media spesimen tumbuhan dan hewan. Salah satu upaya tersebut adalah memberikan penyuluhan kepada guru IPA SMPN 20 Mataram tentang teknik pembuatan spesimen awetan tumbuhan dan hewan.

\section{Metode}

Pengabdian kepada masyarakat di SMPN 20 Mataram dilaksanakan dengan metode diskusi, demonstrasi, dan pendampingan pembuatan spesimen awetan tumbuhan dan hewan. Pengabdian kepada masyarakat di sekolah tersebut dilaksanakan pada bulan September 2020 dengan melibatkan tiga orang dosen, dua orang tenaga laboran biologi, dua orang mahasiswa, dan peserta penyuluhan yang terdiri dua puluh orang guru SMPN 20 Mataram. Peserta penyuluhan tersebut tidak hanya guru IPA tetapi juga guru mata pelajaran lainnya. Macam spesimen yang dibuat menyesuaikan Kompetensi
Dasar dan materi pembelajaran IPA untuk SMP kelas VII, VIII, dan IX, sebagaimana yang terdapat dalam Lampiran Kurikulum 2013 Kompetensi Inti dan Kompetensi Dasar IPA SMP/MTs (Kemdikbud, 2013).

Kegiatan pengabdian kepada masyarakat diawali dengan tahap persiapan, kemudian tahap pelaksanaan, dan terakhir tahap evaluasi kegiatan. Pada tahap persiapan dilakukan diskusi antara tim pengabdian dan guru serta kepala sekolah mitra tentang metode pelaksanaan kegiatan, alat dan bahan yang dipersiapkan serta jadwal kegiatan pengabdian di sekolah.

Tahap pelaksanaan dilakukan dengan memberikan penjelasan tentang pentingnya spesimen awetan tumbuhan dan hewan untuk memperkaya media dan sumber belajar siswa, kemudian mendemonstrasikan cara pembuatan spesimen awetan kering dan basah tersebut, dan mendampingi guru membuat spesimen awetan tumbuhan dan hewan. Jenis spesimen yang dibuat menyesuaikan dengan materi IPA SMP seperti yang tertuang dalam Kompetensi Dasar Kurikulum 2013, serta tumbuhan dan hewan yang mudah ditemukan siswa dalam kehidupan sehari-hari, yaitu spesimen basah dan kering hewan invertebrata (serangga, cacing dan moluska), serta spesimen awetan kering tumbuhan berupa herbarium. Pembuatan spesimen awetan hewan mengacu pada Pratiwi (2013); Istiqomah (2014); Yelianti et al. (2016), sementara pembuatan herbarium mengacu cara yang dikemukakan Murni et al. (2015).

Sebelum pelaksanaan pengabdian masyarakat di sekolah mitra dilakukan, tim pengabdian terlebih dahulu menyusun contoh awetan kering tumbuhan dan hewan berupa herbarium, insektarium, dan awetan cangkang moluska, serta contoh awetan basah berupa awetan ikan, katak, Echinodermata, dan cacing. Selain menyediakan bahan awetan makhluk hidup yang sudah jadi, tim pengabdian juga menyediakan spesimen tumbuhan dan hewan yang belum diawetkan. Spesimen yang belum jadi awetan ini dipergunakan untuk melatih guru membuat awetan hewan dan tumbuhan, seperti beberapa jenis tumbuhan paku dan rumputan, serta hewan seperti capung, kupu-kupu, lebah, belalang dan cangkang hewan moluska. Setelah bahan tumbuhan dan hewan tersedia, baik yang telah diawetkan maupun yang belum, maka kegiatan pengabdian di sekolah siap dilakukan. 
Kegiatan pengabdian kepada masyarakat ini diakhiri dengan tahap evaluasi. Tahapan evaluasi dilakukan dengan mengisi dan menganalisis hasil pengamatan yang ditulis pada lembar pengamatan keterlaksanaan pengabdian serta memberikan angket yang berisi pertanyaan tentang perubahan pemahaman dan keterampilan guru setelah pengabdian dilakukan. Angket evaluasi tersebut juga menanyakan tentang manfaat yang diperoleh guru dalam memperkaya variasi media IPA untuk pembelajaran selama pandemi Covid-19 ini. Respons dari peserta pengabdian terhadap pertanyaan dalam angket dianalisis secara deskriptif.

\section{Hasil dan Pembahasan}

Pelaksanaan pengabdian di sekolah mitra diawali dengan penjelasan dan analisis kurikulum IPA SMP terutama terkait dengan materi biologi. Hasil diskusi tersebut menyepakati bahwa pentingnya penyediaan spesimen awetan tumbuhan dan hewan untuk memperkaya media praktikum dan sumber belajar IPA serta untuk meningkatkan pemahaman siswa terkait dengan keanekaragaman, struktur dan fungsi tumbuhan dan hewan, serta habitat makhluk hidup. Tahap kegiatan berikutnya adalah demonstrasi dan pendampingan pembuatan spesimen awetan tumbuhan dan hewan. Kegiatan ini menghasilkan beberapa spesimen awetan tumbuhan dan hewan walaupun beberapa spesimen awetan yang dibuat belum selesai $100 \%$ misalnya belum pada tahap penyimpanan awetan kering insektarium dan herbarium pada pigura atau kotat penyimpanan awetan. Pada kegiatan pengabdian ini peserta berhasil membuat spesimen awetan kering tumbuhan, awetan kering dan basah hewan, serta spesimen cangkang moluksa. Kegiatan demonstrasi dan pendampingan praktek pembuatan spesimen tumbuhan dan hewan ditunjukkan pada Gambar 1.

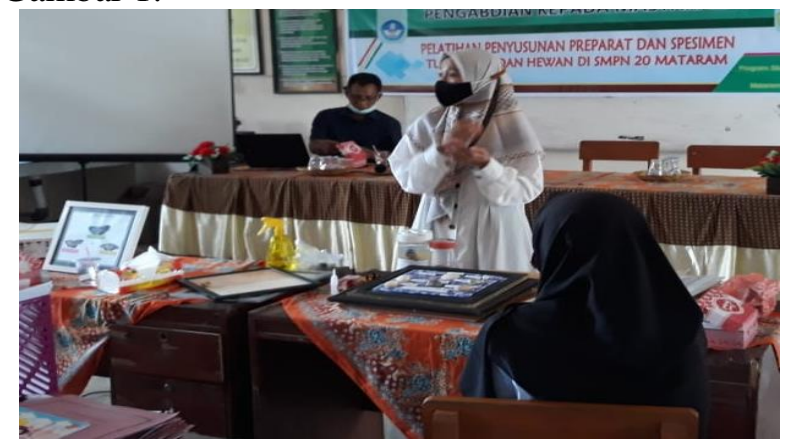

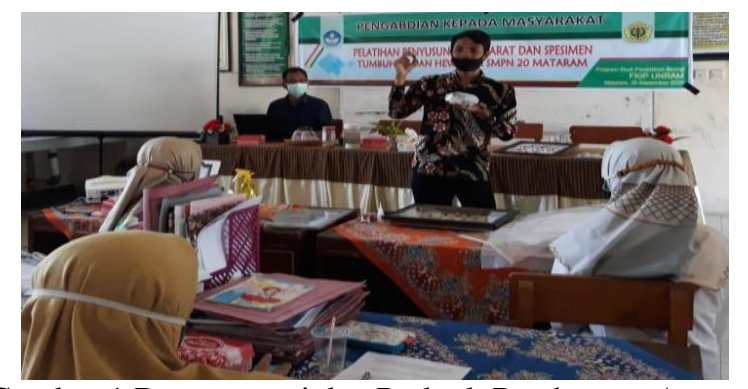

Gambar 1 Demonstrasi dan Praktek Pembuatan Awetan Tumbuhan dan Hewan

Spesimen awetan yang pertama dibuat adalah insektarium. Insektarium dibuat secara sederhana menggunakan alat dan bahan murah dan mudah diperoleh di lingkungan sekitar siswa. Pembuatan awetan secara sederhana adalah pembuatan awetan yang tidak menggunakan bahan kimia yang mahal seperti eter dan formalin tetapi melalui pengeringan atau menggunakan bahan pengawet yang cukup murah harganya seperti alkohol $70 \%$ dan kapur barus sebagai pelindung spesimen dari serangan hewan lainnya, seperti semut. Insektarium berisi kumpulan serangga seperti kupu-kupu, kumbang, belalang, dan serangga lainnya, sehingga herbarium disebut juga sebagai pajangan atau koleksi awetan serangga. Insektarium merupakan media pembelajaran yang membantu peserta didik mempelajari struktur dan ciri dari tubuh serangga secara lebih mendalam. (Susilo, 2017). Penerapan media insektarium mendukung pencapaian Kompetensi Dasar dalam kurikulum 2013 mata pelajaran IPA SMP kelas VII, yaitu KD. 4.2 Menyajikan hasil analisis data observasi terhadap benda (makhluk) hidup dan tak hidup, KD 4.3 Mengumpulkan data dan melakukan klasifikasi terhadap benda-benda, tumbuhan, dan hewan yang ada di lingkungan sekitar.

Tahap pembuatan insektarium dimulai dari mengoleksi bermacam-macam serangga, seperti kupu-kupu, capung, belalang, dan serangga lainnya menggunakan jaring serangga. Serangga kupu-kupu dan capung yang telah dikoleksi kemudian dibunuh dengan cara memencet bagian toraks (dada) kemudian hewan tersebut disimpan pada kertas papilot. Sementara serangga yang mempunyai bagian tubuh yang cukup tebal, seperti belalang, lebah, dan kumbang dibunuh dengan meletakkannya pada botol berisi cairan pembunuh serangga atau disemprot dengan obat pembunuh serangga, seperti baygon, hit, dan lainnya, atau disimpan pada botol atau kantong plastik yang 
kemudian disimpan dalam freezer atau pendingin kulkas. Bagian toraks serangga kemudian disuntikkan alkohol 70\% untuk keperluan pengawetan. Sebelum kupu-kupu atau serangga lainnya dipajang dalam pigura atau kotak penyimpanan serangga maka terlebih dahulu sayap dan kaki serangga direntangkan sedemikian rupa agar tampak tertata rapi serta tampak jelas bagian sayap dan bagian tubuh lainnya seperti ditunjukkan pada Gambar 2.

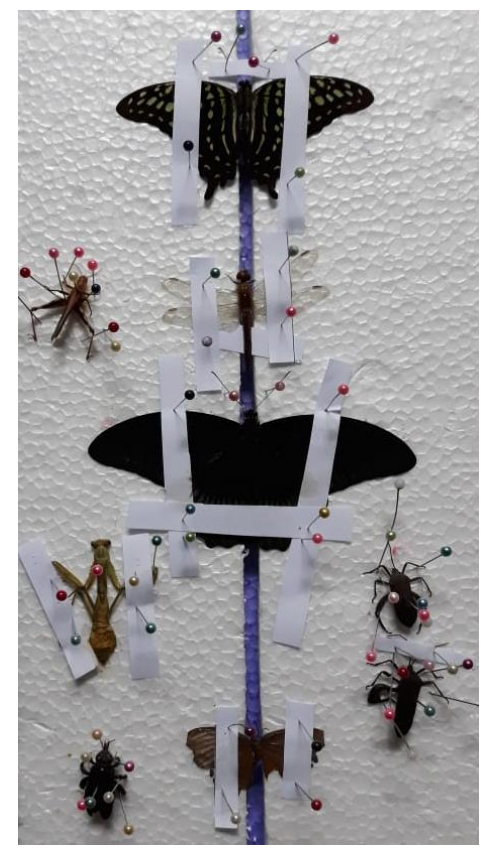

Gambar 2. Perentangan Sayap dan Kaki Serangga

Spesimen awetan yang kedua adalah herbarium. Herbarium adalah spesimen tumbuhan yang dikeringkan (Susilo, 2017). Pada herbarium, disamping disajikan bagian-bagian tubuh tumbuhan juga disajikan keterangan identitas tumbuhan seperti nama, tempat ditemukan, sistematika, dan nama yang mengoleksi, sehingga dalam media herbarium tersajikan informasi tentang struktur tubuh dan habitat tumbuhan. Dengan demikian, herbarium merupakan media pembelajaran yang membantu siswa mempelajari lebih mendalam mengenai struktur akar, batang, daun, bunga dan buah, serta habitat tumbuhan. Sementara bagi guru, herbarium berfungsi membantu guru menunjukkan objek nyata makhluk hidup secara langsung di dalam kelas. Kelebihan penggunaan herbarium sebagai media pembelajaran adalah disamping tersedia informasi bagian tubuh tumbuhan yang lengkap, juga herbarium bersifat ringan dan mudah dipajang di depan kelas, serta dapat disimpan dalam waktu relatif lama. Menurut Mertha et al. (2018), ketersediaan spesimen herbarium di sekolah sangat membantu siswa melakukan analisis sifat dan ciri tumbuhan dalam penentuan keanekaragaman hayati tingkat jenis maupun tingkat gen dengan melakukan pengamatan langsung objek studi tersebut di laboratorium atau di kelas. Pembelajaran yang menggunakan media herbarium adalah mendukung pencapaian Kompetensi Dasar pelajaran IPA SMP kelas VIII, yaitu KD. 3.7 Menjelaskan keterkaitan struktur jaringan tumbuhan dan fungsinya, serta berbagai pemanfaatannya dalam teknologi yang terilhami oleh struktur tersebut, dan KD 4.8 Melakukan pengamatan terhadap struktur jaringan tumbuhan, serta menghasilkan ide teknologi sederhana yang terilhami oleh struktur tersebut (misalnya desain bangunan).

Tahap pembuatan herbarium dimulai dari pemilihan tumbuhan yang akan diawetkan, kemudian membersihkan dari kotoran dengan kuas lembut agar tumbuhan tampak bersih dan tidak mengandung banyak bakteri dan jamur. Tumbuhan yang akan diawetkan kemudian disemprot dengan alkohol $70 \%$ agar tumbuhan tidak mudah busuk. Calon awetan tumbuhan kemudian diletakkan di atas koran dengan posisi yang rapi dengan helaian daun menghadap ke atas dan ke bawah agar terlihat perbedaan struktur permukaan atas dan bawah daun, kemudian tutup bahan dengan koran atau kertas buku. Bahan yang telah terbungkus koran tersebut kemudian dijepit kuat atau ditindih dengan benda berat seperti balok dan buku tebal, Bahan yang telah diproses tersebut selanjutnya disebut dengan spesimen (Gambar 3). Spesimen diletakkan di atas kertas karton lalu direkatkan dengan selotip transparan, kemudian diberi judul dan keterangan untuk memperjelas informasi tumbuhan yang diawetkan. Agar lebih terlindung dan tampak lebih indah, herbarium dimasukkan ke dalam bingkai atau kotak. 


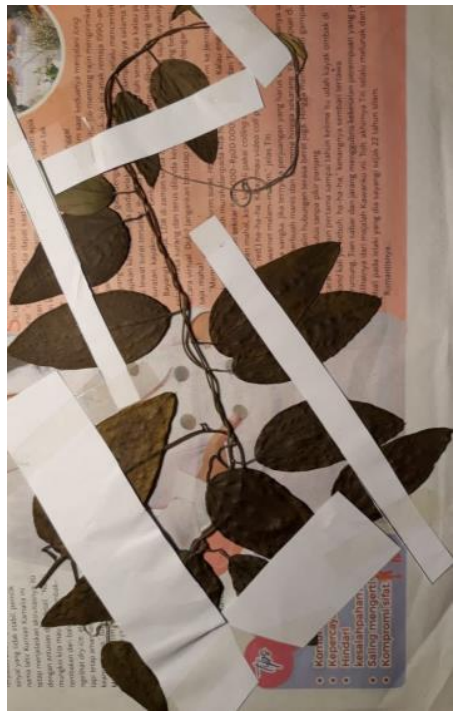

Gambar 3. Spesimen Tumbuhan yang Telah Dikeringkan Spesimen awetan yang ketiga adalah spesimen cangkang moluska. Bagian keras yang disebut cangkang merupakan kerangka luar tubuh hewan moluska, yang difungsikan melindungi tubuh yang lunak di bagian bawah cangkang moluska. Cangkang moluska terbuat dari bahan kapur sehingga keberadaannya dapat bertahan lama walaupun hewan moluska tersebut telah mati. Awetan cangkang moluska berfungsi sebagai media pembelajaran untuk mengenal karakteristik tubuh hewan moluska. Penggunaan media awetan cangkang moluska dalam pembelajaran IPA mendukung pencapaian Kompetensi Dasar dalam kurikulum 2013 mata pelajaran IPA SMP kelas VII, yaitu KD. 4.2 Menyajikan hasil analisis data observasi terhadap benda (makhluk) hidup dan tak hidup, dan KD 4.3 Mengumpulkan data dan melakukan klasifikasi terhadap benda-benda, tumbuhan, dan hewan yang ada di lingkungan sekitar.

Tahap pembuatan spesimen awetan cangkang moluska dimulai dengan mengoleksi hewan muluska hidup atau cangkang yang tidak mengandung hewan hidup, kemudian merendamnya dalam air biasa selama dua jam. Selama perendaman dalam air, hewan yang telah dikoleksi dibersihkan menggunakan sikat gigi. Hewan yang telah dibersihkan direndam dalam air hangat selama 30 menit. Perendaman menggunakan air hangat bertujuan agar tubuh lunak hewan dapat terlepas. Setelah tubuh lunak hewan terlepas, kemudian alkohol $70 \%$ disemprotkan pada cangkang hewan, keringkan di bawah sinar matahari selama sehari. Kotak tempat penyimpanan hewan dikeringkan terlebih dahulu kemudian diberikan e-ticket yang berisikan nama spesies hewan yang dikoleksi. Hewan yang telah kering diletakkan dalam kotak penyimpanan dengan direkatkan menggunakan lem atau alat perekat lainnya. Penempelan e-ticket dilakukan di bawah hewan yang sesuai dengan namanya. Cangkang hewan yang terdapat di dalam kotak disemprot dengan alkohol $70 \%$ secara merata, kemudian diberikan kapur barus di sekeliling kotak penyimpanan.

Spesimen keempat yang dihasilkan dari kegiatan pengabdian ini adalah awetan basah cacing dan ikan. Pembuatan spesimen basah hewan menggunakan bahan pengawet alkohol $70 \%$. Penggunaan bahan pengawet formalin menimbulkan bau kurang sedap dan berbahaya untuk kesehatan, sehingga sebagai penggantinya dapat menggunakan alkohol atau larutan pengawet alternatif yang terdiri garam dapur dengan konsentrasi 1\%; garam PA (Pure Analyst) 0,05\%; gliserin sebesar 0,5\%; dan air suling (Istiqomah, 2014). Penggunaan media awetan basah hewan mendukung pencapaian Kompetensi Dasar dalam kurikulum 2013 mata pelajaran IPA SMP kelas VII, yaitu KD. 4.2 Menyajikan hasil analisis data observasi terhadap benda (makhluk) hidup dan tak hidup, KD 4.3 Mengumpulkan data dan melakukan klasifikasi terhadap benda-benda, tumbuhan, dan hewan yang ada di lingkungan sekitar.

Hasil evaluasi terhadap pelaksanaan pengabdian di SMPN 20 Mataram menunjukkan bahwa peserta pengabdian tampak antusias mengikuti diskusi dan praktek pembuatan spesimen awetan tumbuhan dan hewan. Peserta pengabdian memberikan respons yang positif terhadap pelaksanaan pengabdian. Umumnya peserta mendengarkan penjelasan narasumber dengan serius dan tertarik ikut mencoba membuat awetan tumbuhan dan hewan. Respons peserta dalam kegiatan pengabdian juga terlihat dari jawaban peserta terhadap angket yang diberikan saat penyuluhan. Pertanyaan dalam angket tersebut meliputi pertanyaan tentang proses, manfaat dan tindak lanjut hasil pengabdian kepada masyarakat ini. Jawaban peserta pengabdian terhadap pertanyaan dalam angket tersebut dirangkum dalam Tabel 1. 
Tabel 1. Respons Peserta Pengabdian di SMPN 20 Mataram

\begin{tabular}{ll}
\hline Pertanyaan & Respons Peserta Pengabdian \\
\hline Apakah & Penjelasan dapat difahami, karena \\
penjelasan & informasinya yang disampaikan \\
materi & lengkap serta disertai dengan \\
pengabdian & contoh cara pembuatan yang dapat \\
masyarakat oleh & dipraktekkan secara langsung oleh \\
tim pengabdian & peserta pengabdian saat pelatihan \\
ini mudah & berlangsung. Disarankan oleh \\
dipahami oleh & peserta pengabdian bahwa \\
bapak/ibu guru? & penjelasan dan praktik pembuatan \\
& spesimen awetan makhluk hidup \\
& ini hendaknya juga menyertakan \\
& siswa.
\end{tabular}

Apakah yang

bermanfaat dari

kegiatan

pengabdian ini?

Apakah tindak

lanjut yang

perlu dilakukan

setelah kegiatan

pengabdian

kepada

masyarakat ini?

Manfaatnya adalah guru dapat menambah pengetahuan/ wawasan tentang bagaimana cara membuat awetan tumbuhan dan hewan yang baik. Manfaat lainnya adalah dapat membekali guru keterampilan hidup (life skill) untuk masa yang akan datang guna mendukung profesionalisme guru dalam mengajar, terutama dalam mengembangkan media dan pelaksanaan praktikum yang efektif untuk siswa.

Kegiatan dilanjutkan dengan mengundang siswa untuk ikut diperkenalkan cara mengoleksi dan mengawetkan tumbuhan dan hewan sebagai bahan pelajaran mereka. Disarankan juga apabila pembuatan awetan ini dilanjutkan dengan pembuatan video pembelajaran terkait dengan tugas proyek yang dilakukan siswa, sehingga lebih menantang siswa untuk mengerjakannya dan suasana kerja kolaboratif menjadi lebih ramai dan menarik.

Berdasarkan uraian dalam Tabel 1 tersebut, maka manfaat yang diperoleh guru dalam pengabdian ini adalah peningkatan pengetahuan serta keterampilan guru tentang bagaimana cara membuat awetan tumbuhan dan hewan yang baik. Disamping itu, dapat membekali guru keterampilan hidup (life skill) yang berkontribusi terhadap pengembangan profesionalisme mereka sebagai guru IPA, terutama dalam mengembangkan kemampuan menganalisa dan meningkatkan kreativitas dalam merancang media pembelajaran inovatif yang sesuai dengan materi pembelajaran IPA biologi, serta memberikan ide kreatif guru merancang praktikum dengan memanfaatkan spesimen awetan tumbuhan dan hewan. Hal tersebut sesuai dengan pendapat Sumaraw (2016) bahwa manfaat pendampingan melalui pelatihan adalah meningkatkan wawasan dan profesionalisme guru dalam mengajar.

Hasil pengabdian ini dapat berimplikasi terhadap ide untuk menerapkan pembelajaran kooperatif dengan memberikan tugas mempelajari tumbuhan dan hewan yang dikoleksi siswa. Pemberian tugas siswa untuk mempelajari karakteristik tumbuhan dan hewan melalui tugas proyek pembuatan spesimen tumbuhan dan hewan berkontribusi positif terhadap motivasi dan hasil belajar siswa (Nurhayati \& Harianti, 2020) Menurut Susilo (2017), banyak siswa beranggapan bahwa materi biologi tidak menyenangkan untuk dipelajari karena isinya cenderung menghafal tulisan dan kata latin, sehingga membosankan dan tidak menarik bagi siswa. Lebih lanjut dikatakan bahwa spesimen tumbuhan dan hewan yang diperoleh dari lingkungan sekitar siswa merupakan media pembelajaran yang menarik bagi siswa. Melalui media spesimen tumbuhan dan hewan tersebut, siswa dapat melihat langsung karakteristik tumbuhan dan hewan sehingga pemahaman siswa terhadap struktur tumbuhan dan hewan semakin mendalam. Hal ini akan mendukung pencapaian kompetensi pada KD 4.2 dan 4.3 pelajaran IPA SMP, yaitu tentang ciri-ciri dan klasifikasi makhluk hidup, serta KD 3.7 pelajaran biologi kelas VIII tentang struktur dan fungsi tumbuhan.

Menurut guru IPA SMPN 20 Mataram, siswa sebenarnya dapat mengoleksi dan membuat spesimen awetan tumbuhan dan hewan asalkan diberikan pengarahan yang lengkap bagaimana cara membuat awetan tersebut. Dengan demikian, siswa juga harus memiliki pengetahuan dan keterampilan dalam membuat spesimen awetan tumbuhan dan hewan secara sederhana. Implikasi dari kebutuhan siswa akan pengetahuan dan keterampilan membuat spesimen awetan makhluk hidup adalah tuntutan dimilikinya pemahaman dan keterampilan yang baik dari guru dalam membuat spesimen tumbuhan dan hewan, sehingga memudahkan guru membantu siswa melaksanakan tugas proyek mengoleksi, 
mengawetkan dan mempelajari keanekaragaman, dan struktur dan habitat tumbuhan dan hewan.

\section{Kesimpulan}

Pengabdian kepada masyarakat di SMPN 20 Mataram memberikan dampak terhadap peningkatan pengetahuan dan keterampilan guru membuat spesimen awetan tumbuhan dan hewan. Hasil pengabdian ini berimplikasi terhadap meningkatnya wawasan dan kreativitas guru mengembangkan perencanaan pembelajaran yang memanfaatkan spesimen awetan tumbuhan dan hewan.

\section{Saran}

Pada masa pandemi Covid-19 ini pelaksanaan pembelajaran tidak dapat dilakukan penuh di sekolah melainkan sebagian kegiatan belajar dilakukan di rumah masing masing, sehingga tindak lanjut dari pengabdian ini adalah apabila juga dilakukan pelatihan kepada siswa tentang teknik mengoleksi, mengawetkan dan membuat video tentang struktur dan perilaku tumbuhan dan hewan, sehingga dapat berefek memperkaya jenis kegiatan belajar siswa di rumah serta menunjang terciptanya pembelajaran IPA yang bermakna.

\section{Ucapan Terima Kasih}

Ucapan terima kasih disampaikan kepada Universitas Mataram yang telah mendanai kegiatan pengabdian kepada masyarakat melalui sumber dana DIPA BLU Universitas Mataram tahun anggaran 2020 dengan surat perjanjian nomor 1915/UN18/LPPM/2020. Ucapan terima kasih pula disampaikan kepada kepala sekolah dan guru SMPN 20 Mataram atas fasilitasi kegiatan pengabdian serta antusiasme peserta selama pengabdian kepada masyarakat berlangsung.

\section{Daftar Pustaka}

Agustina, P. (2017). Persepsi Guru Biologi SMA tentang Media Pembelajaran Materi Kingdom Animalia. Proceeding Biology Education Conference, 14(1), 318 - 321.

Artayasa, I P., Muhlis, Hadiprayitno, G., Merta, I W., \& Karnan. (2019). Pengembangan Tes
Keterampilan Proses Sains Untuk Pembinaan Olimpiade Sains Di SMPN 20 Mataram. Jurnal Pengabdian Magister Pendidikan IPA, 2(1), 11-16.

Feyzioglu, B. (2009). An Investigation of the Relationship between Science Process Skills with Efficient Laboratory Use and Science Achievement in Chemistry Education. Journal of Turkish Science Education, 6(3),114-132.

Istiqomah, U. (2014). Pengembangan Media Awetan Basah Cacing Endoparasit dan LKS untuk Pembelajaran Biologi Kelas X. Bioedu. 3(3), 542-549. Diperoleh dari https://media.neliti.com/media/publication s/245363-pengembangan-media-awetanbasah-cacing-e-f48caa30.pdf

Kemdikbud. (2013). Kompetensi Dasar SMP/MTs Kurikulum 2013, Diperoleh dari https://www.academia.edu/6441738/Kom petensi_Inti_dan_Kompetensi_Dasar_Kuri kulum_2013_SMP_dan_MTs.

Mertha, I G., Idrus, A. A., Ilhamdi, L, \& Zulkifli, L. (2018). Pelatihan Teknik Pembuatan Herbarium Kering dan Identifikasi Tumbuhan Berbasis Lingkungan Sekolah Di SMAN 4 Mataram. Jurnal Pendidikan dan Pengabdian Masyarakat. 1(1), 82-87. Diperoleh dari https://core.ac.uk/download/pdf/23467304 3.pdf

Murni, P., Muswita, Harlis, Yelianti, U \& Kartika, W.D. (2015). Lokakarya Pembuatan Herbarium untuk Pengembangan Media Pembelajaran Biologi di MAN Cendikia Muaro Jambi. Jurnal Pengabdian pada Masyarakat 30(2),1-6.

Nurhayati, A. S \& Harianti, 2020. Model Pembelajaran Project Base Learning. Diperoleh dari https://sibatik.kemdikbud.go.id/inovatif/as sets/file_upload/pengantar/pdf/pengantar_ 5.pdf

Pratiwi, P. (2013). Manajemen Koleksi Biota Laut. Jakarta: Puslit Oseanografi LIPI.

Rati, N. W., Kusmaryatni, N., \& Rediani, N.(2017). Model Pembelajaran Berbasis Proyek, Kreativitas dan Hasil Belajar Mahasiswa.Jurnal Pendidikan Indonesia. 6(1), 60-71. 
Sumaraw, S. (2015). Pentingnya Pendampingan Untuk Meningkatkan Kompetensi, Diperoleh dari (https://manadopostonline.com/read/2016/ 07/11/Pentingnya-Pendampingan-untukMeningkatkan-Kompetensi/15232).

Susilo, M. J. (2015). Analisis Kualitas Media Pembelajaran Insektarium dan Herbarium untuk Mata Pelajaran Biologi Sekolah Menengah. Jurnal BIOEDUKATIKA, 3(1), 10-15. Diperoleh dari http://journal.uad.ac.id/index.php/BIOED UKATIKA/article/view/4141

Syamsiah, Nurhayati, B., Hiola, S. F. (2020). Pemanfaatan Spesimen Herbarium sebagai Media Pembelajaran Bagi Guru-Guru IPA/Biologi di Kabupaten Enrekang. Jurnal Dedikasi, 22(1), 99-103.

Yelianti, U., Hamidah, A., Muswita, \& Sukmono, T. (2016). Pembuatan spesimen Hewan dan Tumbuhan Sebagai Media Pembelajaran di SMP Se Kota Jambi. Jurnal Pengabdian pada Masyarakat. 31(4), 36-43. 